\title{
Oficinas de Programação com Ambientes Lúdicos para Meninas do Ensino Fundamental
}

\author{
Suenny Mascarenhas Souza, Mirela dos Santos Rios, Carlos Alberto Rodrigues, \\ David Moisés Barreto dos Santos, Roberto Almeida Bittencourt \\ ${ }^{1}$ Universidade Estadual de Feira de Santana (UEFS) \\ Av. Transnordestina, s/n - 44.036-900 - Feira de Santana - BA - Brasil \\ \{suenny.s, mirelasrios\}@gmail.com, \{carod, davidmbs, roberto\}@uefs.br
}

\begin{abstract}
Low interest and scarce engagement of women in the area of information technology (IT) has triggered various studies and initiatives to better understand the reasons to this context, and to propose changes that lead to a better gender balance in the area. Presenting IT to women during their childhood or teenage years is one of such initiatives, intending to reduce prejudices and combat negative stereotypes. In this paper, we present our experience with computing programming workshops for girls in an elementary school, using the Scratch environment. To analyse the results, workshop tutors produced onboard journals, reporting their impressions in each workshop day. The main lessons learned were: proposed challenges stimulated creativity and investigation by the students; the use of Scratch and games attracts attention and help to maintain interest; we identified games and activities better suited to girls' tastes. Although we faced some challenges with logic reasoning and group work, we ended up in a workshop format that is reasonably stimulating and attractive to girl students of elementary education.
\end{abstract}

Resumo. O baixo interesse e o pouco engajamento feminino na área de tecnologia de informação (TI) têm levado a vários estudos e iniciativas para compreender as razões deste contexto e propor mudanças em direção a um melhor equilíbrio de gênero na área. Uma das alternativas propostas consiste em apresentar a área de TI durante a infância e adolescência de meninas, reduzindo preconceitos e combatendo estereótipos negativos. Neste trabalho, realizamos oficinas de programação de computadores com meninas em uma escola do ensino fundamental utilizando o ambiente lúdico de programação Scratch. Para analisar os resultados, produzimos diários de bordo relatando as impressões das tutoras em cada dia da oficina. As principais lições aprendidas foram: os desafios propostos estimulam a criatividade e instigam o espírito investigativo das estudantes; o uso de jogos e o ambiente Scratch atraem a atenção $e$ o interesse das meninas; identificamos alguns jogos e atividades adequados aos gostos das alunas. Apesar de algumas dificuldades relacionadas a raciocínio lógico e trabalho em grupo, conseguimos chegar a um formato de oficina razoavelmente estimulante e atraente para meninas estudantes do ensino fundamental.

\section{Introdução}

Os trabalhadores da área de tecnologia de informação (TI) são predominantemente do sexo masculino. Tanto é pequena a proporção de mulheres em cursos de graduação em 
computação como é ainda menor a de mulheres que atuam na área de TI [Teague 2002]. Atualmente, há uma grande carência no preenchimento das vagas dos empregos de TI por graduados na área [Observatório Softex 2012]. Portanto, havendo maior interesse de mulheres em seguir carreiras de TI, acredita-se que pode-se solucionar parcialmente esta carência. Alguns autores entendem que o aumento da participação feminina na computação é um fator importante para promover equidade e assegurar que as mulheres possam desfrutar das oportunidades deste ramo [Ashcraft et al. 2012]. Além disso, é necessário assegurar que o futuro da TI seja amplo e inovador. Estudos na área de gênero argumentam que a participação de mulheres traz novos olhares e perspectivas para os diversos ramos do conhecimento [Schwartz et al. 2006]. Ademais, várias empresas têm enfatizado a importância de uma força de trabalho mais equilibrada entre os dois sexos nos seus cargos ligados à computação, por acreditarem que a diversidade de perspectivas permite servir melhor a seus usuários internos e externos bem como a atender à sua base de clientes [Ash et al. 2009].

Esta predominância masculina na área, muitas vezes, é resultado de decisões prévias na infância e adolescência. Pesquisas sugerem que os estudantes decidem, entre onze e treze anos de idade, com quais disciplinas têm afinidade e em quais eles são bons [Denner 2011]. Este mesmo estudo aponta que meninos têm mais confiança e maior interesse nas áreas de computação do que meninas. Por outro lado, Teague (2002) descobriu que meninas não têm muito interesse em seguir carreiras relacionadas à computação - Geralmente, este fato está vinculado aos estereótipos associados à computação e a percepções errôneas a respeito das carreiras desta área [Teague 2002]. Ao entrar no ensino médio, meninas tendem a ver a computação como uma carreira chata, difícil, para nerds, e onde se trabalha socialmente isolado [Outlay et al. 2012]. Pesquisas sugerem que estas percepções e estereótipos precisam ser atacados o quanto antes, de preferência o mais cedo possível, como na educação fundamental, por exemplo. Meninas que participam de programas educacionais relacionados a TI têm maior propensão a terem atitudes positivas e uma boa compreensão da natureza do trabalho na Computação [Outlay et al. 2012].

O presente trabalho parte dessa perspectiva, de estimular o quanto antes o interesse das estudantes pela área de computação. Na experiência aqui relatada, realizamos três oficinas de aprendizagem de programação com o uso do ambiente lúdico Scratch. As oficinas tiveram doze horas de duração cada e contaram com a participação de meninas entre dez e doze anos de idade. Voltadas apenas para meninas e tutoradas por duas estudantes de um curso de Engenharia de Computação, as oficinas foram realizadas em uma escola pública estadual do ensino fundamental. As tutoras produziram diários de bordo reflexivos em cada dia de oficina de modo a entender e refletir melhor sobre o processo de ensino-aprendizagem.

Para uma melhor compreensão, o artigo está organizado como descrito a seguir. A Seção 2 discute trabalhos relacionados ao nosso. Em seguida, a Seção 3 descreve o planejamento das oficinas, e os resultados são apresentados na Seção 4. A Seção 5 relata lições aprendidas. O artigo é encerrado com as conclusões e sugestões de trabalhos futuros. 


\section{Trabalhos Relacionados}

Segundo o censo dos grupos de pesquisa do CNPq de 2002, a proporção de mulheres atuantes no meio acadêmico nas áreas de engenharia e ciência da computação fica em torno de 30\% [Cabral and Bazzo 2005]. Esta proporção não é muito diferente nos cursos de graduação em todo o mundo: dados coletados em cerca de trinta países sobre a presença feminina em cursos de computação revelam que a proporção de mulheres neste ramo na maioria dos países varia entre $10 \%$ e $40 \%$ [Galpin 2002]. No Brasil, uma análise dos dados da Pesquisa Nacional por Amostra de Domicílios (PNAD) de 2009 aponta que a porcentagem de mulheres nas profissões de ciência e tecnologia que atuam como profissionais e técnicas é, respectivamente, de $18,5 \%$ e $11 \%$ [Olinto 2011].

Uma survey realizada com 1710 participantes investiga o perfil das mulheres estudantes e profissionais de computação do Brasil [Oliveira et al. 2014]. Os resultados mostram que suas disciplinas preferidas na escola foram Matemática, Física e Língua Estrangeira, nesta ordem. Os principais motivos para suas escolhas de carreira foram: o gosto por atividades matemáticas e de raciocínio, as perspectivas de mercado e as oportunidades de trabalho em áreas diversas. As profissionais mencionaram sofrerem preconceito ou discriminação às vezes (44\%), enquanto as estudantes que deram esta mesma resposta foram $30 \%$, sugerindo que o mercado apresenta mais problemas de discriminação do que a academia.

Meninas geralmente possuem atitudes mais negativas em relação aos computadores e são retratadas como possuindo menos autoconfiança que meninos [Abbiss 2008]. Os estereótipos existentes nas famílias, nos grupos sociais e na mídia também são fatores que contribuem para uma visão masculinizada da computação [Abbiss 2008]. Além disso, a falta de autoconfiança das meninas pode impedi-las de se engajarem no ramo. A literatura relata que meninas são geralmente mais tímidas que os meninos. Estes, por sua vez, possuem uma atitude mais exploratória [Gürer and Camp 2002].

A compreensão sobre o que atrai as mulheres para a computação auxilia no planejamento de estratégias de recrutamento [Carmichael 2008]. Uma pesquisa qualitativa envolvendo 18 departamentos de universidades nos Estados Unidos reúne uma série de razões pelas quais estudantes de computação do sexo feminino escolheram este ramo [Cohoon 2002]. Esta pesquisa ainda sugere que intervenções feitas pelas universidades, com atividades e programações para as escolas, podem ser bem eficazes, inclusive eliminando estereótipos masculinos associados à computação.

Nesse mesmo sentido, outras formas de atração de meninas para a área estão sendo continuamente exploradas. O projeto "Girls on the GO: The Mobile Computing College Experience", realizado na universidade de Miami, ensina programação para meninas do ensino médio, procurando encorajar o interesse feminino pela ciência da computação de várias maneiras. Além de mostrar a flexibilidade do trabalho em computação, as atividades deste projeto procuram exercitar a criatividade. O foco é o design de um aplicativo para celular que possa ser utilizado por pesquisadores para documentar e estudar o comportamento de animais [Burge et al. 2013].

Um outro projeto procura desenvolver um currículo de computação para meninas do ensino médio baseado no construtivismo, onde as estudantes aprendem melhor ao criar algo tangível [Marcu et al. 2010]. Buscando aumentar a autoconfiança e interesse 
de meninas pela área, os autores deste trabalho desenvolveram e testaram um curso de computação de quatro semanas para alunas do ensino médio. Neste curso, utilizaram kits PicoCrickets, que combinam conceitos básicos de programação, dispositivos eletrônicos e design.

No Brasil, alguns projetos vêm sendo realizados com este mesmo objetivo de fomentar o interesse feminino pela área da Computação. O projeto Meninas Digitais, que realiza palestras, visitas e outras iniciativas pelo Brasil, relata um experimentopiloto em uma escola pública de Cuiabá, com atividades na área de interação humanocomputador com nove alunas adolescentes, objetivando contribuir com a divulgação da computação neste universo. O projeto aborda o design de interfaces a partir de atividades de computação desplugada [Maciel et al. 2012]. Ainda na área de interação humanocomputador, um minicurso foi realizado para meninas do ensino médio de uma escola pública de Guarapuava-PR. O minicurso utilizou conceitos de engenharia semiótica e objetivou apresentar às adolescentes um espaço da computação que não lidava apenas com o aspecto tecnológico [Bim 2011].

\section{Planejamento das Oficinas de Programação para Meninas}

Descrevemos a seguir, primeiramente, o ambiente de programação utilizado, Sratch, e depois, o planejamento propriamente dito das oficinas.

\subsection{Scratch}

Scratch é um ambiente desenvolvido no Media Lab do Instituto de Tecnologia de Massachussetts. Ele possui uma linguagem gráfica de programação inspirado nas linguagens Logo e Squeak. Para atingir seus objetivos de introduzir programação para crianças e adolescentes, Scratch possui os seguintes princípios de design: ser mais manipulável, mais significativo e mais social [Resnick et al. 2009]. Para ser mais manipulável, Scratch utiliza uma linguagem baseada em blocos similar aos blocos existentes em brinquedos Lego. Para ser mais significativo, permite criar uma diversidade de projetos (e.g., jogos, animações, simulações, representações) e importar e criar uma variedade de mídias. Para ser mais social, permite que projetos sejam compartilhados e remixados através de uma rede social.

Scratch permite criar projetos que controlam gráficos, animações, texto e áudio, podendo interagir ainda com objetos externos. A programação é realizada através de scripts montados pelo encaixe dos blocos de comando que são agrupados nos seguintes temas: movimento, aparência, som, caneta, controle, sensores, operadores e variáveis. Assim, torna-se simples criar jogos e animações. A manipulação dos blocos é intuitiva e realizada através de manipulação direta com mouse e teclado. A rede social do Scratch permite compartilhar e reutilizar outros projetos feitos e compartilhados por pessoas ao redor do mundo, oferecendo inspiração, suporte e interação aos usuários do ambiente.

\subsection{Planejamento}

As oficinas de programação propostas foram adaptadas a partir da experiência prévia de outras oficinas realizadas por nosso Grupo de Aprendizagem de Programação da UEFS - Universidade Estadual de Feira de Santana. Nosso grupo oferece, desde 2012, oficinas de programação em escolas do município de Feira de Santana e na própria UEFS. Entretanto, esta oficina se diferenciou por trabalhar exclusivamente com o público feminino. 
Além disso, as alunas eram provenientes de turmas da sexta série do Centro Integrado de Educação Assis Chateaubriand, escola estadual da educação básica, tendo o conteúdo das oficinas sido adaptado para a faixa etária das participantes.

A descrição geral das oficinas consta da Tabela 1. Esperávamos que, ao final delas, as participantes fossem capazes de desenvolver pequenas aplicações e jogos no ambiente Scratch, expressando-se de maneira flexível através do computador. De modo indireto, objetivou-se também oferecer uma nova perspectiva às participantes de que a computação pode ser algo divertido, interessante e desafiador. Um total de 23 alunas da sexta série do ensino fundamental se inscreveu nas oficinas, sendo divididas em três turmas. Duas tutoras, estudantes de Engenharia de Computação da UEFS, com experiência prévia no ensino em outras oficinas, guiaram o processo de ensino-aprendizagem. As oficinas tiveram doze horas de duração e foram realizadas em um período de três semanas, sempre no turno oposto ao das aulas regulares. A metodologia consistiu de uma exploração do ambiente Scratch guiada por desafios propostos pelas tutoras na forma de animações e jogos.

Tabela 1. Descrição das oficinas.

Oficinas de Programação com Ambientes Lúdicos para Meninas

\begin{tabular}{|l|l|}
\hline Objetivos & $\begin{array}{l}\text { Ser capaz de desenvolver pequenas aplicações e jogos no ambi- } \\
\text { ente Scratch, expressando-se de maneira flexível através do com- } \\
\text { putador. }\end{array}$ \\
\hline Metodologia & $\begin{array}{l}\text { Aprendizagem através de descoberta do ambiente Scratch, gui- } \\
\text { ada por desafios propostos pelas tutoras na forma de animações e } \\
\text { jogos voltados para meninas. }\end{array}$ \\
\hline Conteúdo & $\begin{array}{l}\text { Scripts em Scratch. Sensores e apresentação. Seleção e repetição. } \\
\text { Variáveis, expressões lógicas e aritméticas. Comunicação entre } \\
\text { objetos. }\end{array}$ \\
\hline Tutoras & $\begin{array}{l}\text { Duas estudantes do curso de Engenharia de Engenharia de } \\
\text { Computação. }\end{array}$ \\
\hline Local & $\begin{array}{l}\text { Laboratório de Informática do CIEAC - Centro Integrado de } \\
\text { Educação Assis Chateaubriand. }\end{array}$ \\
\hline Participantes & $\begin{array}{l}\text { Alunas da sexta série do ensino fundamental de escola pública } \\
\text { estadual. }\end{array}$ \\
\hline Período & 3 semanas. \\
\hline Carga Horária & 12 horas, divididas em 3 sessões de 4 horas. \\
\hline Turmas & 3 turmas com, respectivamente, 6, 7 e 10 alunas. \\
\hline
\end{tabular}

As animações e jogos propostos levaram em conta os gostos de meninas entre dez e doze anos, elicitados através de um brainstorming com as alunas participantes em nosso grupo de pesquisa e extensão. A primeira atividade foi uma animação com o gato personagem do Scratch. As duas outras atividades foram os jogos clássicos Pong e Pacman, simplificados para a duração das sessões da oficina e a faixa etária. O Pacman foi adaptado para uma Pacwoman, para garantir identidade das participantes com os jogos. A Tabela 2 detalha cada dia de oficina, em termos de objetivos, projeto realizado e conteúdos trabalhados. 
Tabela 2. Planejamento resumido da oficina.

\begin{tabular}{|c|c|c|c|}
\hline Aula & Objetivos & Projeto & Conteúdo \\
\hline $1^{\circ} \mathrm{Dia}$ & $\begin{array}{l}\text { Ao final desta sessão, as } \\
\text { participantes devem ser } \\
\text { capazes de navegar com } \\
\text { um bom domínio da ferra- } \\
\text { menta, compreendendo o } \\
\text { que o ambiente oferece e } \\
\text { onde encontrar o que pre- } \\
\text { cisam. }\end{array}$ & $\begin{array}{l}\text { Animação com o gato } \\
\text { personagem do Scratch. }\end{array}$ & $\begin{array}{l}\text { Inserção de objetos. } \\
\text { Troca de cenários. } \\
\text { Comandos de } \\
\text { aparência } \\
\text { movimentação. } \\
\begin{array}{l}\text { Comunicação entre } \\
\text { objetos. }\end{array}\end{array}$ \\
\hline $2^{\circ} \mathrm{Dia}$ & $\begin{array}{l}\text { Ao final da sessão, as } \\
\text { participantes devem ser } \\
\text { capazes de construir um } \\
\text { jogo simples, utilizando } \\
\text { o raciocínio lógico e } \\
\text { os conceitos básicos de } \\
\text { programação. }\end{array}$ & $\begin{array}{l}\text { Jogo Pong: jogo 2D } \\
\text { que simula uma partida } \\
\text { de squash, simplificado } \\
\text { para apenas uma joga- } \\
\text { dora. }\end{array}$ & $\begin{array}{l}\text { Estruturas de seleção. } \\
\text { Estruturas de } \\
\text { repetição. } \\
\text { Leitura de sensores. } \\
\text { Operadores lógicos e } \\
\text { relacionais. } \\
\text { Variáveis. }\end{array}$ \\
\hline $3^{\circ} \mathrm{Dia}$ & $\begin{array}{l}\text { Ao final desta sessão, as } \\
\text { alunas devem ser capazes } \\
\text { de criar um jogo mais } \\
\text { complexo, aprofundando } \\
\text { alguns conceitos de } \\
\text { programação, especial- } \\
\text { mente sobre variáveis. }\end{array}$ & $\begin{array}{l}\text { Jogo Pacwoman: } \\
\text { adaptação do jogo } \\
\text { clássico Pacman onde } \\
\text { o personagem come } \\
\text { biscoitos num labirinto. }\end{array}$ & $\begin{array}{l}\text { Repetição e fortale- } \\
\text { cimento dos concei- } \\
\text { tos trabalhados nas } \\
\text { sessões anteriores. }\end{array}$ \\
\hline
\end{tabular}

Nestas oficinas, coletamos dados das percepções das tutoras sobre as motivações destas meninas em relação às atividades e em relação à área de TI. Ambas as tutoras registraram suas observações e percepções em diários de bordo escritos imediatamente após o final de cada sessão das oficinas.

\section{Resultados}

Como em outras experiências em escolas públicas brasileiras, tivemos de adaptar a oficina à realidade existente. A escola parceira possui um laboratório de informática com pouca disponibilidade de computadores funcionais. Assim, foi necessário trabalhar com duplas ou até mesmo trios. Isto, entretanto, levou a uma dificuldade em convencer meninas préadolescentes a trabalhar em grupo. Esta questão foi relevante, sendo necessários que as tutoras contornassem frequentemente pequenos conflitos entre as participantes.

No primeiro dia, propôs-se um projeto de uma animação com o gato personagem do Scratch. As participantes foram desafiadas a criar um cenário e distribuir este e outros personagens neste cenário, criando um diálogo entre eles. Com este projeto, as participantes puderam aprender a manipular os comandos básicos da ferramenta e seus diferentes temas, realizar a troca de cenários, a inserção de objetos e até mesmo pequenas comunicações simples entre estes objetos. 
No segundo dia de oficina, o projeto proposto foi o jogo Pong, um jogo 2D simulando uma partida de squash com apenas uma jogadora. No desenvolvimento deste jogo, as participantes reforçaram e aprofundaram os conceitos de comunicação entre objetos aprendidos na primeira sessão, além de utilizar largamente estruturas de seleção e repetição, leitura de sensores, operadores lógicos e relacionais e começar a usar os conceitos de variáveis para contagem do placar.

No último dia da oficina, o desafio proposto foi a construção do jogo Pacwoman, cujo objetivo é conseguir comer todos os biscoitos de um labirinto sem ser devorada por fantasmas. Este último jogo, apesar de mais complexo, teve como finalidade apenas reforçar os conceitos aprendidos pelas participantes nas sessões anteriores, além de apresentar os benefícios de ser um jogo mais atrativo e divertido.

As participantes demonstraram empolgação visível ao desenvolver as animações, especialmente ao criar brincadeiras com o movimento do gato personagem do Scratch. Ao deixá-las livres para criar cenários, trajes e animações, elas se mantinham bastante concentradas e determinadas a cumprir os desafios. Elas também demonstraram motivação ao desenvolver o projeto da Pacwoman, aparentando alegria ao fazer desenhos dos biscoitos e frutas necessários ao jogo.

Por outro lado, as participantes tinham dificuldade em dividir o trabalho. Era necessária a intervenção das tutoras em qualquer atividade, como, por exemplo, para definir quem utilizaria o mouse ou teclado, ou para acatar uma decisão sobre cores escolhidas, nomes de personagens ou diálogos realizados. Este comportamento das estudantes foi constatado em todas as sessões das oficinas, o que acabou reduzindo o desempenho do grupo e tornando o progresso das aulas mais lento.

Uma outra questão importante foi como lidar com dificuldades na interpretação dos desafios e na lógica de programação demandada para a criação de projetos como Pong e Pacwoman. Várias alunas não conseguiam compreender imediatamente o funcionamento do Scratch. Uma parte delas não conseguia entender a necessidade de alguns blocos ou não entendia a ordem em que os blocos deveriam ser encaixados para que o programa funcionasse da forma desejada. A dificuldade maior foi no uso dos blocos de sensores e variáveis. Nestes caso, elas apresentavam muitas dúvidas e, muitas vezes, não conseguiam caminhar sozinhas. Foi possível perceber, durante o desenvolvimento do Pong, que a maior parte das meninas parecia desestimulada, não se apresentavam investigativas e curiosas, preferiam aguardar que um novo desafio fosse lançado para que desenvolvessem algo. Este jogo, previsto para ser concluído em uma única sessão, acabou sendo construído em uma sessão e meia. As tutoras sentiram que foram muitos conceitos para uma só sessão. Pela própria idade das participantes, e diferente de outras oficinas que nosso grupo realizou com adolescentes, as meninas demonstravam uma grande necessidade de aprovação daquilo que produziam, só passando para a próxima etapa após aprovação feita pelas tutoras.

Por outro lado, percebeu-se, dentre o grupo de 23 participantes, que duas delas demonstraram extrema facilidade em aprender e realizar os desafios. Muitas vezes, estas duas iam além dos desafios, incrementando o projeto com aspectos adicionais ou concluindo o proposto na metade do tempo que o restante da turma necessitava. 


\section{Lições Aprendidas}

Um aprendizado importante com a realização destas oficinas é sobre o planejamento de aulas. Conhecendo-se o público-alvo (e.g., faixa etária, sexo, experiência com computadores), deve-se realizar uma pesquisa detalhada e preparar os projetos, atividades e conteúdos de cada sessão de maneira minuciosa, buscando atender a este público tanto no quesito facilidade de compreensão como em aspectos específicos como capacidade de manter atenção, estímulos necessários, dentre outros. Por exemplo, percebemos que o jogo Pong não foi atraente para o público de meninas pré-adolescentes, enquanto que as animações e o jogo Pacwoman foram bem-vindos. Provavelmente, o jogo Pong não será usado nas próximas oficinas.

As sessões de oficina no modo "desafio", bem como o uso de jogos, instigaram a criatividade e o espírito investigativo das alunas. A utilização de desafios, em especial, é interessante por evitar exposições desnecessárias de conteúdos formais. Contudo, as atividades propostas devem ter dimensionamento apropriado, para não levar à monotonia ou ao cansaço, pois alunas de sexta série são pré-adolescentes com necessidades específicas de dinâmica e atenção.

Sem dúvida, Scratch é um ambiente simples para crianças e adolescentes. Sendo um ambiente proposto para tarefas lúdicas, ele torna as atividades mais divertidas naturalmente. Todavia, deve-se estar atento às dificuldades apresentadas pelas alunas, tanto em relação a habilidades de programação como em relação ao uso da ferramenta.

Nestas oficinas para alunas de sexta série, observou-se a necessidade de mais tutoras para auxiliar as alunas, por sua inquietude própria da idade. É preciso também refletir sobre a própria capacitação das tutoras para trabalhar com meninas entre 10 e 12 anos de idade, já que elas não são estudantes de cursos de licenciatura para o ensino fundamental, não conhecendo a fundo as questões de desenvolvimento próprias da idade das participantes. Entendemos que seria útil também a presença de um pesquisador-observador, para fazer anotações importantes sobre o contexto de cada aula, pois os diários de bordo, apesar de fornecerem uma boa base de dados, apresentaram apenas as perspectivas das tutoras. As observações podem fornecer dados mais imparciais, descrevendo de forma mais detalhada os acontecimentos importantes de cada oficina.

Uma percepção das tutoras é de que faltou fazer uma atividade de conscientização das participantes sobre o que é a área da Computação e o que é a programação de computadores. Isto permitiria formalizar alguns conceitos, ainda que de modo intuitivo, em relação às carreiras da área de TI. Uma possibilidade seria, no decorrer ou ao final das sessões, abordar não somente a construção dos projetos e o desenvolvimento do raciocínio lógico das participantes, mas também deixar claro que estas atividades e habilidades que elas estão desenvolvendo são diretamente relacionadas com carreiras do setor de TI.

\section{Conclusões}

Este artigo relatou uma experiência de oficinas de programação de computadores para meninas do ensino fundamental, utilizando um ambiente lúdico de aprendizagem de programação. Descrevemos objetivos, metodologia e demais aspectos ligados ao planejamento das oficinas, relatamos os resultados obtidos a partir da análise dos diários de bordo produzidos pelas tutoras ao final das sessões das oficinas, e ainda apontamos 
as lições aprendidas neste processo. Os resultados expõem algumas dificuldades encontradas relacionadas ao planejamento das oficinas e ao comportamento das participantes pré-adolescentes. Expõem também o interesse e motivação elevados pelo uso de um ambiente lúdico de aprendizagem e por uma metodologia baseada em descoberta e desafios. Finalmente, algumas lições aprendidas foram destacadas para melhor planejar atividades futuras com este mesmo público.

Concluímos que as oficinas foram bem recebidas pelas participantes, e percebemos que é possível trabalhar habilidades e conceitos básicos de programação de maneira descontraída e divertida. O formato de sessões baseadas em desafios, o uso da ferramenta Scratch e os projetos baseados em jogos tornam as atividades atrativas. Contudo, devemos buscar mais jogos que se adequem melhor ao perfil das participantes. Do ponto de vista de infraestrutura, sentimos dificuldades com as poucas máquinas no laboratório, o que impediu a utilização de um computador por participante.

Estamos reformulando o planejamento das atividades, desde os projetos aplicados até o número de tutores. Estamos também construindo instrumentos de pesquisa na forma de questionários, guias de entrevista e um protocolo de observação, que devem ser aplicados na próxima oferta destas oficinas. Com isto, esperamos conseguir realizar oficinas cada vez mais estimulantes para as participantes, despertando-as para a utilização ativa do computador na construção de programas de acordo com seus interesses. Pretendemos ainda, realizar novas oficinas de programação com alunas não só do ensino fundamental, mas também do ensino médio.

\section{Agradecimentos}

Este projeto contou com o apoio da FAPESB - Fundação de Amparo à Pesquisa do Estado da Bahia - e da UEFS - Universidade Estadual de Feira de Santana, na forma de bolsas de iniciação científica e de extensão.

\section{Referências}

Abbiss, J. (2008). Rethinking the 'problem' of gender and IT schooling: discourses in literature. Gender and Education, 20(2):153-165.

Ash, R. A., Coder, L., Dupont, B., and Rosenbloom, J. L. (2009). Examining the obstacles to broadening participation in computing: Evidence from a survey of professional workers. Contemporary Economic Policy, 27(3):413-421.

Ashcraft, C., Eger, E., and Friend, M. (2012). Girls in IT : the facts. In SIGCSE ' 13 Proceeding of the 44th ACM technical symposium on Computer science education, page 79.

Bim, S. A. (2011). Uma experiência de ensino de Interação Humano-Computador para alunas do ensino médio. In Anais do XXXI Congresso da SBC. XIX Workshop sobre Educação em Computação, pages 1670-1679.

Burge, J., Gannod, G., Doyle, M., and Davis, K. (2013). Girls on the go: a CS summer camp to attract and inspire female high school students. In Proceeding of the 44th ACM technical symposium on Computer science education - SIGCSE' '13, pages 615-620.

Cabral, C. and Bazzo, W. (2005). As Mulheres nas Escolas de Engenharia Brasileiras: História, Educação e Futuro. Revista de Ensino de Engenharia, 24(1):3-9. 
Carmichael, G. (2008). Girls, computer science, and games. ACM SIGCSE Bulletin, 40(4):107.

Cohoon, J. M. (2002). Recruiting and retaining women in undergraduate computing majors. ACM SIGCSE Bulletin, 34(2):48.

Denner, J. (2011). What Predicts Middle School Girls' Interest in Computing? International Journal of Gender Science and Technology, 3(1):53-59.

Galpin, V. (2002). Women in computing around the world. ACM SIGCSE Bulletin, 34(2):94.

Gürer, D. and Camp, T. (2002). An ACM-W literature review on women in computing. ACM SIGCSE Bulletin, 34(2):121.

Maciel, C., Bim, S. A., and Boscarioli, C. (2012). A Fantástica Fábrica de Chocolate: levando o sabor de IHC para meninas do ensino fundamental. In IHC ' 12 Companion Proceedings of the 11th Brazilian Symposium on Human Factors in Computing Systems, pages 27-28.

Marcu, G., Kaufman, S. J., Lee, J. K., Black, R. W., Dourish, P., Hayes, G. R., and Richardson, D. J. (2010). Design and evaluation of a computer science and engineering course for middle school girls. In Proceedings of the 41 st ACM technical symposium on Computer science education - SIGCSE' '10, pages 234-238.

Observatório Softex (2012). Software e Serviços de TI: A indústria Brasileira em Perspectiva, volume 2 .

Olinto, G. (2011). A inclusão das Mulheres nas Carreiras de Ciência e Tecnologia no Brasil. Revista Inclusão Social, 5(1):68-77.

Oliveira, A. C., Moro, M. M., and Prates, R. O. (2014). Perfil Feminino em Computação: Análise Inicial. In Anais do XXXIV Congresso da SBC. XXII Workshop de Educação em Computação, pages 1465-1674, Brasília, DF. SBC.

Outlay, C., Ambrose, P., and Chenoweth, J. (2012). Overcoming Gender Stereotype Entry Barriers To Computing Degree Programs : The Cybergirlz. Journal of Computing Sciences in Colleges, 28(1):33-38.

Resnick, M., Maloney, J., Hernández, A. M., Rusk, N., Eastmond, E., Brennan, K., Millner, A., Rosenbaum, E., Silver, J., Silverman, B., and Kafai, Y. (2009). Scratch: Programming for All. Communications of the ACM, 52(11):60-67.

Schwartz, J., Casagrande, L. S., Leszczynski, S. A. C., and Carvalho, M. G. D. (2006). Mulheres na informática: quais foram as pioneiras? Cadernos Pagu, 27:255-278.

Teague, J. (2002). Women in computing: what brings them to it, what keeps them in it? ACM SIGCSE Bulletin, 34(2):147-158. 